\title{
Globalização, atividade empresarial e a segurança jurídica ${ }^{1}$
}

Adyr Garcia Ferreira Netto ${ }^{2}$

\section{Resumo}

O presente artigo pretende analisar o conceito de atividade empresarial, relacionando doutrina econômica e jurídica. Comentam-se as implicações derivadas da sua imersão na globalização, e as questões pertinentes ao princípio da segurança jurídica e a certeza do direito. Relaciona-se a segurança jurídica e a certeza do direito com a instabilidade e falta de diretrizes legais e objetivas, inerentes ao contexto da economia global que a atividade empresarial inexoravelmente se submete.

Palavras-Chave: Globalização; Atividade empresarial; Segurança jurídica e certeza do direito.

\section{Introdução}

Qualquer sistema econômico para satisfazer suas necessidades de produção, tem como base a exploração das reservas naturais, o trabalho humano e os recursos instrumentais (ROSSETI, 1992, p. 90).

No entanto, a alocação geográfica destas fontes de geração de riqueza, principalmente as reservas naturais, não está distribuída igualmente pelo mundo, o que impôs aos povos a condição de negociar entre si a troca de produtos e serviços, dando origem ao comércio internacional. Com o advento da tecnologia, este processo se intensificou e derrubou as barreiras da distância e do tempo para o transporte das pessoas, de produtos e de informações entre países distantes.

Esta ruptura de fronteiras entre os povos atingiu um grau de magnitude com a atual globalização, que desafia os sistemas jurídicos legalistas ao oferecê-lo a cada momento, um novo paradigma social passivo de revisão interpretativa, pois este engendra relações novas,

1 Este texto reúne as principais idéias do 3. o capítulo da dissertação "O DIREITO NA ECONOMIA GLOBALIZADA: A influência da globalização nas relações sociais e seus reflexos na atividade empresarial". Pressupõe a lógica deste tópico, que o leitor já obteve através do contato prévio com os capítulos antecedentes, o conceito de globalização. No entanto, a leitura se iniciada aqui, não sofrerá prejuízo para alcançar os objetivos propostos: Compreender o significado de atividade empresarial, suas implicações no processo de globalização e, analisar a segurança jurídica na economia global.

2 Mestrando em Direito Negocial, UEL/2007. (adyr@sercomtel.com.br) 
tipicamente jurídicas, que estão além da competência territorial da legislação local e da capacidade de previsibilidade normativa. Sob o mesmo ponto de vista, a integração econômica mundial permite ao mercado internacional, bem como à especulação financeira, percorrer um terreno sem lei, trazendo graves conseqüências à estabilidade econômica e jurídica dos estados nacionais.

\section{Conceito de atividade empresarial}

Dentro da atividade humana, aquela direcionada à produção e circulação de bens e serviços, de forma racional e ordenada, chama-se empresarial. Esta é uma idéia que remonta a doutrina econômica clássica de Jean Babtiste Say (apud SHUMPTER, 1997, p. 84) "A função do empresário é combinar fatores produtivos, reuni-los", considerando a distinção fundamental entre empresário e capitalista que é aceita até os dias de hoje, pois aquele organiza os meios de produção, tem sensibilidade e visão estratégica diante dos negócios, e este é proprietário do dinheiro, de direitos ao dinheiro ou de bens materiais. Essa distinção traz confusão à pessoa sem formação econômica, pois nos primórdios do capitalismo, no mesmo indivíduo se concentrava as qualidades do capitalista e de empresário, o que é comum ainda hoje, mas a distância conceitual entre eles é a mesma que medeia o patrão e o empregado. Não se deve tratar então, a atividade empresarial como sinônimo de capitalismo, embora esteja inserida no mesmo contexto.

Na doutrina econômica, é inevitável falar de empresário ou atividade empresarial sem associá-los ao estudo de Joseph Alois Schumpeter em sua obra "Teoria do desenvolvimento econômico", que condiciona os ciclos econômicos ao espírito empreendedor do empresário, ou seja, o impulso na curva de ascensão da economia dependerá da visão e das propostas inovadoras do espírito empresarial, caso contrário, a economia correria o risco de permanecer em um equilíbrio estático sem crescimento real. Para Schumpeter (1997), empresário é o indivíduo que tem a função de realizar as combinações novas do meio de produção, sendo novas combinações aquelas necessárias para o desenvolvimento econômico e a saída do equilíbrio estático, fruto do seu espírito empreendedor.

A ciência econômica avançou ainda mais e criou mecanismos de medição da atividade econômica, representada pelo PNB ou produto nacional bruto, que informa sobre 76

Revista de Direito Público, LondRINA, V. 2, N. 1, P. 75-88, JAN./ABR. 2007. 
a renda total do país e a totalidade das despesas feitas na produção de bens ou serviços (MANKIW, 1992, p. 10), ou ainda, “... expressa o valor agregado bruto das empresas, que corresponde ao total da produção de bens e serviços finais a preços de mercado" (ROSSETI, 1992, p. 556). Assim, é possível não somente conceituar, mas medir a atividade empresarial.

No entanto, não é necessário para este trabalho pormenorizar nos moldes schumpeterianos as qualidades definidoras de empresário, tampouco buscar nas ciências econômicas a definição e mensuração econométrica da atividade empresarial, pois o que se pretende é tratar tal atividade como uma conduta humana movida por interesses próprios, e ao dar o suporte material à sociedade, determina a sorte e a dignidade dos indivíduos quando podem desfrutar ou não dos bens e serviços oferecidos por ela. $O$ fato das pessoas estarem inseridas ou não neste sistema vital, é matéria de interesse jurídico constitucional, como se pode verificar nos artigos 3. ํ, 6. ํ, 170 e incisos da CRFB (Constituição da República Federativa do Brasil).

Sob o ponto de vista funcional, a atividade empresarial ganha dimensões diferentes da racionalidade estratégica peculiar da economia, pois deixa de ser mero instrumento lucrativo, para assumir a responsabilidade de promover uma sociedade mais justa.

No âmbito jurídico para onde converge o interesse deste trabalho, mas seguindo de perto o caminho já traçado pela doutrina econômica, o Código Civil brasileiro reconhece o empresário como aquele que profissionalmente organiza a produção ou a circulação de bens e serviços e, ainda que a legislação não traga uma definição específica para a atividade empresarial, infere-se pelo que se considera empresário, o que seja sua atividade (ROSSETI, 1992, p. 17).

Harmonizar racionalmente o fluxo destes fatores produtivos a fim de constituírem um processo permanente e em equilíbrio, sem destruir as reservas naturais, explorando estrategicamente o capital através da livre iniciativa, respeitando o homem e o meio em que vive, constituem alguns princípios desta atividade econômica reconhecidos pela constituição, o que implica em condições para o exercício da atividade empresarial, dando à ela um novo status, pois passa a cumprir papel ativo na sociedade ao promover não só progresso econômico, mas também o desenvolvimento social, pois até então era mero objeto de estudo, descrito pelas ciências econômicas. 
É possível concluir pela lógica e unidade do ordenamento jurídico brasileiro, que as ciências econômicas devam não apenas descrever fatos econômicos ou estudar passivamente as relações de mercado. Ainda que o aspecto normativo da economia não seja novidade, pois o Estado a programa e planeja através de políticas econômicas desde há muito tempo, a função social em que todos os membros da comunidade civil, não só as entidades políticas, mas também os indivíduos devam estar empenhados a cumprir, é idéia recente, que surge a partir da constituição de 1988 (ROSSETI, 1992, p. 17). Para explorar a economia, a constituição oferece a liberdade, mas não permite a licenciosidade.

Diante destas considerações, tolerando para fins didáticos a tautologia a seguir, entende-se atividade empresarial aquela que se destina a coordenar os fatores de produção, ou seja, coordenar aqueles elementos indispensáveis ao processo produtivo de bens materiais, como a terra, o trabalho humano e o capital, prerrogativa exclusiva, conforme o Código Civil, do empresário profissional (SANDRONI, 1999, p. 235). Em sua vertente jurídica, este conceito deve satisfazer ainda os princípios constitucionais da ordem econômica e os ditames da justiça social, representando não mais uma estratégia específica de mercado para obtenção de lucro, mas a consciência de um setor vital que tem vontade própria e poder de determinar o destino e a dignidade de toda uma nação.

\section{A atividade empresarial inserida na economia globalizada}

A atividade empresarial, no entanto, transcende a dimensão territorial que alcança a constituição, pois o advento do progresso tecnológico que viabilizou a economia global permitiu também ao empresário estender seus negócios além das fronteiras físicas e jurídicas, atingindo simultaneamente vários lugares nos quais, muitas vezes as leis não foram desenvolvidas e fundamentadas nos mesmos valores e ideais que o histórico jurídico constitucional pátrio legitimou. Há que considerar ainda que grande parte do capital mundial concentra-se no mercado financeiro, cuja mobilidade criou o que conhecemos atualmente por capitalismo global, pois somente o histórico do comércio internacional de bens e serviços não seria capaz de motivar a integração econômica nas proporções que conhecemos hoje (SOROS, 1999, p.154). 
Por ser ainda mais volátil do que os investimentos físicos, o capital financeiro ocupa uma posição privilegiada: ele é capaz de evitar países onde esteja sujeito a sistemas tributários ou regulamentares onerosos. Uma vez construída, é difícil mudar a localização de uma fábrica. Sem dúvida, as corporações multinacionais desfrutam da flexibilidade dos preços de transferência e são capazes de exercer pressões no momento da decisão sobre o investimento, mas sua maleabilidade não se compara com a liberdade de escolha dos investidores em carteiras internacionais (SOROS, 1999, p. 154).

Este ambiente de liberdade incondicional que o capital atinge na economia globalizada reflete nos interesses econômicos do setor empresarial, como exemplo, o capital financeiro não estando adstrito a territorialidade e nem a princípios, pois não se fala em "função social do capital especulativo", encontra caminho livre para alcançar taxas de retorno jamais obtidas no investimento em capital produtivo. Para se ter uma idéia, "O mercado financeiro ganhou proporções descabidas. Enquanto o comércio internacional (a compra e venda de produtos) movimenta 6 trilhões de dólares em um ano inteiro, o capital financeiro especulativo movimenta 1,8 trilhão por dia..." ${ }^{3}$, implicando em forte influência nas decisões pertinentes da atividade empresarial. Pela proporção entre o investimento no mercado financeiro e produtivo, depositar esperanças de uma sociedade mais justa apenas em um princípio abstratamente incidente na propriedade privada no Brasil é visão extremamente limitada sobre um universo sem fim.

O que se pretendeu neste exemplo, é evidenciar que se a especulação financeira é incomparavelmente mais atrativa do que o investimento no setor produtivo, e ao migrar para este setor em volumes imensos, o capital evidencia sua obstinação de satisfazer interesses próprios, agindo estrategicamente para atingir seu único fim: O lucro.

O capital produtivo também possui a sua mobilidade, estruturas físicas de grandes empresas com seus trabalhadores qualificados podem rapidamente mudar de cidade, de estado, de país, conforme suas conveniências e expectativas de lucro, adaptando-se aos lugares onde a lei seja mais branda, a tributação menos onerosa, onde o trabalhador possa ser mais explorado, onde sindicalismo não tenha força política. Sua sede administrativa protege-se das responsabilidades, mas seus produtos alcançam o mundo e competem desigualmente com a concorrência menos flexível e excluída do processo da globalização.

\footnotetext{
3 Whitaker, Ferreira, João Sette. Disponível em: <http://www.fau.usp.br/docentes/depprojeto/j_whitaker/Attacrede.html>. Acesso em: 18 jul. 2006.
} 
Esta mobilidade dos fatores de produção ganha força à medida que as empresas dispõem de recursos para investir em tecnologia, advindos da exclusão competitiva do concorrente no processo histórico de concentração de capital, típica dos moldes da autofagia capitalista prevista por Karl Marx através do conceito de mais-valia extraordinária.

A guerra da concorrência faz-se baixando cada qual os preços o mais possível. A barateza dos produtos depende, sendo iguais as demais circunstâncias, da produtividade do trabalho, e esta da escala das empresas. Os Grandes capitais derrotam os pequenos.

[...] Num ramo de produção particular, a centralização não chegaria ao seu último limite senão no momento em que todos os capitais individuais que nela estivessem empenhados, não formassem mais que um só capital individual (MARX, 1962, pp. 334-335).

O sobre-valor utilizado para se reinvestir na própria estrutura a fim de ganhar em termos tecnológicos da concorrência, é chamado de mais-valia extraordinária, fruto de uma tendência do capital se auto-valorizar indefinidamente:

A concorrência entre diferentes capitalistas conduz sempre à introdução de máquinas aperfeiçoadas, máquinas de produtividade superior à média, e os capitalistas que primeiro as utilizam podem apropriar-se de uma mais-valia extra, pois estão em condições de produzir mercadorias mais baratas do que os seus competidores, mesmo que as vendam ao mesmo preço (ou pouco mais barato). $\mathrm{O}$ valor individual é então inferior à média social ${ }^{5}$.

Se um empresário ou setor da atividade empresarial não se esforçasse ou desviasse sua atenção do caminho da obtenção de lucro, certamente entraria em bancarrota e desapareceria do mercado. Não se questiona o fim lucrativo da atividade empresarial, mas quando para isso são utilizados meios causadores de desigualdades sociais, destruição de recursos naturais, danos à dignidade e aos direitos humanos, a intervenção legal deve surgir, pois a natureza humana sendo incapaz de se auto-limitar, pede auxílio ao poder judiciário para restabelecer a ordem e a justiça.

\footnotetext{
4 O espírito científico desta obra não tem compromisso com ideologia de qualquer natureza, a citação de qualquer pensador ou doutrina, será feita por conviç̧ão de sua adequação teórica as necessidades da discussão em tela. O resgate de apontamentos do matiz doutrinário que separa os entusiastas da direita ou esquerda, de modo algum compromete a coerência e a lógica argumentativa que se pretende realizar. Em outras passagens da dissertação, haverá defesa, por motivos lógicos e não ideológicos, da liberdade no seu mais amplo sentido, como a livre iniciativa, liberdade de concorrência, liberdade de possuir bens e outros.

5 COLETIVO DA UNIVERSIDADE DE BERLIM. O guia para entender o capital, p, 80, 81.
} 
Este é um aspecto negativo da atividade empresarial inserida na globalização, logo, objeto de interesse ao estudo do direito. Os inúmeros aspectos positivos não são citados por não gerarem lides, controvérsias, ou motivações para regramento de conduta.

A atividade empresarial submetida à economia globalizada enfrenta ambiente hostil, tornando-se mais agressiva na utilização de mecanismos de sobrevivência competitiva, o que desperta atenção do judiciário, uma vez que o mercado é fundamental para se construir uma sociedade justa, livre e solidária.

\section{Questões sobre segurança jurídica e certeza do direito para o cenário globalizado}

Tratar da segurança jurídica ${ }^{6}$ tendo como base a Constituição brasileira, que pretende ser, não apenas um rol de prescrições escritas, mas a instituição de um Estado Democrático destinado a assegurar a justiça, liberdade, igualdade, bem estar, desenvolvimento, direitos sociais e individuais e a segurança, como diz em seu preâmbulo, é tarefa difícil.

As leis jurídicas se diferenciam das demais formas normativas por trazerem a sanção que inibe ou surge como resposta à violação da prescrição jurídica. Nos moldes desta proposta constitucional, não é possível estabelecer uma correlação imediata e proporcional à violação de um princípio de justiça com uma sanção perfeitamente estipulada e prevista no texto escrito, pelo fato de que as sociedades se tornam cada vez mais complexas, o advento tecnológico acelera as mudanças sociais e, elevar as relações fáticas ao status de relações jurídicas através da normatização, é processo moroso. Para agravar este paradigma de mutação constante, se a capacidade imaginativa do homem para transgredir leis positivadas é grande, para violar princípios, é imensurável.

Norberto Bobbio (2001, p. 152) traz em sua obra "Teoria da Norma Jurídica" um interessante estudo que aponta a sanção como o critério lógico para resposta à violação da lei, ou seja, para trazer segurança e eficácia ao cumprimento da norma. Esta conclusão é irrefutável, pois historicamente nenhuma sociedade se mostrou racional o suficiente para seguir leis por simples adesão e reconhecimento de que a lei é boa e deva ser seguida, se assim fosse, o legislador somente editaria normas para organizar a sociedade, e o direito deixaria de existir, pois a justiça seria um senso natural.

\footnotetext{
6 Vide artigo 5 . . incisos XXXVI a LXXIII, a positivação do princípio de segurança jurídica na CRFB.
} 
Tal sociedade não existe, mas ao contrário, o espírito criativo do homem se volta contra os princípios de justiça, e na medida em que as relações tornam-se mais complexas, a arte de enganar e de corromper é cada vez mais sutil, mais esmerada.

A economia globalizada proporciona à regulação da atividade empresarial, um cenário ainda mais grave, pois além de acrescentar uma variável extradogmática que é o compromisso de promover desenvolvimento social, enfrenta um conjunto de dois elementos ainda indomados pelo homem e inalcançados pelas leis, que são o mercado e a liberdade de fronteiras.

Variável "extradogmática" tem seu fundamento na idéia de Lourival Vilanova (2003, p. 464), quando aborda o tema da função jurisdicional dos direitos em uma sociedade em desenvolvimento, de forma não concentrada no interior do sistema jurídico, o que "[...] importa em sair do ordenamento, sair da órbita do jurídico, do normativo. O que é importante".

O mercado, como já se tratou, tem interesses próprios, e a tentativa de conscientizar o empresário que sua atividade tem sérias implicações para promover a justiça social, enquanto é árdua em um território definido e regulado por uma jurisdição, o que dizer quando se tem a total liberdade e isenção de fronteiras jurídicas da economia mundial? Há que se considerar ainda, que a política brasileira até os dias de hoje se acomodou em anunciar como resultado positivo de uma gestão qualquer, números do progresso econômico, como se o mero crescimento e incremento técnico fosse sinônimo de qualidade e desenvolvimento social. É certo que não se tem desenvolvimento sem progresso, mas não faz sentido extrair o progresso do trabalho de um povo, e não retribuí-lo de forma digna e qualitativa.

Em outras palavras, se o direito enfrenta dificuldades de promover 0 desenvolvimento social em uma sociedade dinâmica dentro de uma territorialidade limitada, tornam-se ainda mais desafiadoras quando a influência e a força do Estado perdem autonomia em face da integração econômica mundial.

A atividade empresarial enquanto instrumento de geração do desenvolvimento é objeto de estudo do direito econômico, que consiste em um "[...] conjunto de normas do sistema do direito positivo ou a própria ciência que se ocupa do seu estudo, que tem por objeto a juridicização da política econômica do Estado" (SILVA NETO, 2002, p. 160). No 
entanto, as diretrizes das políticas econômicas encontram-se nas normas constitucionais programáticas, como o exemplo do artigo 170 da $\mathrm{CRFB}^{7}$ e, destacar os problemas relativos à segurança jurídica e a certeza do direito quando estas normas pretendem modificar a realidade social, torna-se abordagem fundamental na lógica deste tópico. As políticas específicas para regulação e fiscalização da atividade econômica no âmbito do comércio internacional e no mercado interno, serão objeto de outro estudo, que pretende trazer uma análise dos mecanismos e instrumentos jurídicos modernos do direito econômico.

Como bem notou Lourival Vilanova, as sociedades em processo de desenvolvimento lento, o ordenamento jurídico é capaz de responder satisfatoriamente aos reclames da vida social, pois,

as novas situações encontram solução normativa dentro dos quadros gerais do ordenamento: as regras legisladas, os regulamentos editados, as decisões judiciais vão, cada uma em sua esfera própria, criando o direito novo, sem quebra dos lineamentos e contornos do ordenamento jurídico total (VILANOVA, 2003, p. 464).

No entanto, nas sociedades em processo de desenvolvimento acelerado, para proteger os direitos fundamentais, adotar um ponto de vista estático do ordenamento jurídico à semelhança dos sistemas formais, seria insuficiente para solucionar os casos emergentes das situações imprevisíveis (VILANOVA, 2003, p. 473).

Como proporcionar segurança jurídica à sociedade em relação aos valores constitucionais, quando a fonte provedora de recursos materiais está inserida em um paradigma que a força da lei pouco tem eficácia? Eis uma face da crise da legalidade, pois as sociedades regradas pelos ordenamentos formalistas ficaram dependes do Estado para Ihes dizerem o que é direito, e acomodadas na idéia de que tudo é permitido se não for proibido, quando não há normas específicas e as respectivas sanções, o abuso é inevitável.

A existência do direito consiste na idéia de segurança jurídica, pois os indivíduos de uma sociedade necessitam saber quais seus deveres e obrigações quando se relacionam com os demais, e quais suas expectativas em relação ao Estado quando este tem o poder de puni-lo quando se dá a violação de uma norma prevista no ordenamento ${ }^{8}$.

Conforme Alexandre de Moraes, normas programáticas traçam preceitos a serem cumpridos pelo Poder Público, como "programas das respectivas atividades, pretendendo unicamente a consecução dos fins sociais pelo Estado"(MORAES, 2004, p. 45).

8 Estas idéias motivaram o contratualismo na filosofia política dos séculos XVI, XVII e XVIII. 
A certeza jurídica advém de normas, que possibilitam a previsão, dentro de um marco de probabilidade, da conduta dos indivíduos e da conduta dos agentes do poder. A medição normativa da conduta alcança sua forma típica no Estado-dedireito. Dentro dos limites do direito, movem-se governantes e governados. Elimina-se a irracionalidade da conduta arbitrária, quer nas decisões do poder, quer nas relações recíprocas dos indivíduos (VILANOVA, 2003, p. 471).

Esta previsibilidade gera a segurança jurídica, e a freqüência em que a norma positivada é aplicada na vida prática, gera o sentimento de certeza do direito, enquanto aquela surge de forma objetiva, através da formalização de regras, esta surge subjetivamente, quando o indivíduo passa a confiar que o direito sempre será aplicado. Como exemplo, se há uma lei que pune a corrupção, esta evidencia o aspecto da segurança jurídica quando anuncia expressamente a conduta reprovável e sua respectiva sanção, na medida em que os corruptos são punidos, a certeza do direito se consolida no espírito do cidadão. O cenário inverso tem efeitos semelhantes, pois ainda que a impunibilidade não afete a segurança jurídica, destrói a certeza do direito, e daí a crise de legalidade, pois esta surge não somente pela falta de adequação normativa aos novos paradigmas de uma sociedade em desenvolvimento acelerado, mas de uma carência da credibilidade do direito instituído.

A segurança jurídica só é possível no Estado de Direito com a previsibilidade das leis escritas, no entanto, a tradição do direito formal não consegue responder satisfatoriamente como meio de regulação de toda a proposta da democracia constitucional. É importante ressaltar, que para dirimir as questões ordinárias do cidadão comum, o formalismo é fundamental e necessário, pois não há como se imaginar a supressão das formalidades dos procedimentos processuais ou da legislação existente, sem graves prejuízos à sociedade, uma vez que este modelo jurídico sempre fez parte da cultura local.

Nas questões pertinentes ao cenário da atividade empresarial na economia globalizada, como se viu, é inviável diante da sua mobilidade e da sua capacidade de mudança, criar-se leis adequadas para cada situação nova, resta a possibilidade de se obter a certeza do direito, que é o reflexo e termômetro da eficácia jurídica, sem necessariamente estar condicionada a uma conexão entre o fato e a lei positiva, ou seja, criar na consciência do cidadão, mais especificamente no empresário que, embora não haja para um dado de fato no mundo concreto, a subsunção em um tipo normativo perfeitamente descrito na legislação, há princípios norteadores da conduta humana, que devem ser exigidos pela força 
da coerção do Estado, da mesma forma e rigor que se aplica as prescrições típicas do positivismo.

Nesta linha de raciocínio, César Garcia Novoa (2000, p. 29) faz o seguinte comentário:

En el Estado de Derecho la Constitución deja de entenderse como uma simple articulación formal de poderes, para ser um parágrafo de los valores materiales de todo el ordenamiento, Es asi como hay que compreender una visión substancial de la seguridad jurídica basada em uma concepción también sustancial de la legalidad. La substancialización de la seguridad jurídica em el marco del Estado de Derecho es producto de la própria sustancialización de este tipo de Estado, pues la única forma de garantizar la primacia total de la Constitución es abandonar la idea de um Estado puramente legal, para passar a ver al Estado de Derecho como um estado inspirado por um conjunto de princípios constitucionales, y em el que las normas jurídicas, fruto de la voluntad general, se someten a um cânon de razonabilidad.

A força de coerção de que se tratou, fundamenta-se na proposta da constituição quando institui um Estado Democrático que assegura os princípios preambulares, admitindo implicitamente uma ideologia do desenvolvimento, o que implica a necessária intervenção do Estado no domínio econômico, e uma política para aplicação do programa desenvolvimentista.

O desenvolvimento é um progresso global, que mobiliza fatores diversos (educacional, econômico, tecnológico, científico, social) dentro de um quadro planejado com previsão normativa. O desenvolvimento requer planejamento, interligação das variáveis sociais (melhor, sociológicas), recursos financeiros e econômicos, investimentos que ultrapassam a capacidade econômica dos particulares, ação racionalizada (planejamento), direção do processo, em vez da espontaneidade do livre jogo dos fatores econômicos, e vontade ou decisão de mudança. [...] Na história do mundo atual, é sobretudo o Estado que tem condições de assumir a empresa do desenvolvimento global, integral, racionalizado. Pois o desenvolvimento implica numa decisão: tem de haver uma política do desenvolvimento [...] (VILANOVA, 2003, p. 469).

Para esta missão, apresenta-se então uma teoria geral da regulação da economia, através de princípios e fundamentos jurídicos. É uma proposta sugerida por Calixto Salomão Filho (2001, p. 13), que em sua obra "Regulação da atividade econômica", apresenta como via alternativa da tradicional concepção de Estado como agente de duas funções diametralmente opostas: a ingerência direta na vida econômica e a mera fiscalização dos particulares. 
Esta via alternativa é uma resposta ao paradigma dicotômico tradicional que tem de um lado a esfera privada, de outro, uma estatal que entendia a regulação somente como uma questão procedimental de funcionamento das agências reguladoras e órgãos de defesa de concorrência (SALOMÃO, 2001, p. 14), passando dar ao Estado a função de organizador das relações sociais e econômicas, como agente motivador da atividade empresarial para redirecioná-la no caminho do desenvolvimento ${ }^{9}$, e não mais como mero instrumento para policiar os mercados.

Este entrelaçamento entre as esferas privadas e públicas modificando o paradigma tradicional da organização social dicotômica dá um novo fôlego à certeza do direito, pois visa a aplicabilidade de princípios constitucionais na vida prática da atividade empresarial, seja no território nacional, ou no plano da integração econômica mundial, através de uma teoria jurídica da regulação, gerando ao menos, nova expectativa em relação à credibilidade do direito.

\section{Conclusão}

As considerações expostas sobre as implicações jurídicas engendradas pela inserção da atividade econômica na economia globalizada, possibilitam as seguintes conclusões:

1) A atividade empresarial perante a nova ordem constitucional representa uma vontade e uma consciência da classe dos empresários que deve assumir responsabilidades perante os princípios preambulares previstos na Carta Magna, deixando de ser meramente um ramo da economia que tem como único fim o lucro;

2) A atividade empresarial inserida na economia globalizada enfrenta ambiente hostil, cujo meio de competição exige a utilização de mecanismos radicais para o crescimento e manutenção da empresa;

3) As taxas de lucro advindas da especulação financeira atraem volumes imensos de recursos monetários, implicando em diminuição do interesse de investir no setor produtivo, e das expectativas em relação ao desenvolvimento econômico futuro;

9 Embora pareça ser um eufemismo para a intervenção do Estado de modo a planificar a economia, não é isso que se pretende, pois o intuito do raciocínio converge tão somente na intervenção do poder público na atividade empresarial, a fim de fazê-la cumprir os princípios constitucionais para a ordem econômica, ainda que permaneça nos moldes tradicionais de uma ideologia liberal na produção material da sociedade. 
4) As mudanças aceleradas na sociedade propiciam uma interação entre sujeitos cada vez mais complexa, dificultando a previsibilidade típica dos ordenamentos legalistas;

5) Elevar as novas relações de fato a relações jurídicas através da criação e adaptação constante de normas é tarefa inviável em função da velocidade e dinamismo das mudanças sociais;

6) A segurança jurídica é fragilizada perante o processo dinâmico de mudanças sociais e das novas relações internacionais motivadas pela globalização; e,

7) O resgate da certeza do direito pode ser obtido através da intervenção do Estado e da compreensão do direito como instrumento ativo para exigir o cumprimento dos princípios preambulares da CRFB.

\section{Referências}

BOBBIO, Norberto. Teoria da norma jurídica. São Paulo: Edipro, 2001.

COLETIVO DA UNIVERSIDADE DE BERLIM. O guia para entender o capital. Lisboa: Antídoto, 1978.

MANKIW, N.GREGORY. Macroeconomia.Rio de Janeiro: LTC, 1992.

MARX, Karl. O capital. Rio de Janeiro: Melso,1962.

MORAES, Alexandre. Direito constitucional. 15. ed. São Paulo: Editora Atlas, 2004.

NOVOA, César Garcia. El princípio de seguridad jurídica em matéria tributaria. Madrid: Marcial Pons, 2000.

ROSSETTI, José Paschoal. Introdução à economia. 17.ed. São Paulo: Atlas, 1992.

ROSSETTI, José Paschoal. Políticas e programação econômicas. 7.ed., São Paulo: Atlas, 1993.

SALOMÃO FILHO, Calixto. Regulação da atividade econômica: princípios e fundamentos jurídicos. São Paulo: Malheiros, 2001.

SANDRONI, Paulo. Novíssimo dicionário de economia. 2. ed. São Paulo: Best Seller, 1999. 
SHUMPETER, Joseph Alois. Teoria do desenvolvimento econômico: Uma investigação sobre lucros, capital, crédito, juro e ciclo econômico. São Paulo: Nova Cultural, 1997. (Coleção os economistas).

SILVA NETO, Manoel Jorge. Globalização e direito econômico. In: LEÃO, Aroldo; PAMPLONA FILHO, Rodolfo. Globalização e direito. Rio de Janeiro: Forense, 2002.

SOROS, George. A crise do capitalismo. Rio de Janeiro: Campus, 1999.

VILANOVA, Lourival. Escritos jurídicos e filosóficos. São Paulo: Axis Mundi: Ibet, 2003. v. 2.

WHITAKER, Ferreira, João Sette. Disponível em: <http://www.fau.usp.br/docentes/depprojeto/j_whitaker/Attacrede.html>. Acesso em: 13 mar. 2006. 